\title{
Phenomenological Study Regarding the Consequences of Job Relocations
}

\author{
Mirwan Surya Perdhana ${ }^{1, *}$, Dian Ratna Sawitri², Danang Edmirendy Surya \\ Permana $^{3}$ \\ ${ }^{1}$ Faculty of Economics and Business and Center for Career and Capacity Development Studies, (CAREERS), \\ Diponegoro University Jl. Prof. Soedarto, S. H., Tembalang, Semarang 50275, Central Java, Indonesia \\ ${ }^{2}$ Faculty of Psychology and Center for Career and Capacity Development Studies (CAREERS), Diponegoro \\ University Jl. Prof. Soedarto, S. H., Tembalang, Semarang 50275, Central Java, Indonesia \\ ${ }^{3}$ Faculty of Economics and Business, Diponegoro University Jl. Prof. Soedarto, S. H., Tembalang, Semarang \\ 50275, Central Java, Indonesia
}

*Corresponding author. Email: mirwan@live.undip.ac.id

\begin{abstract}
The aim of this study is to investigate employee's perceptions of job relocation in Alpha Corp, a government organization with representative office located in all provinces in Indonesia. Despite the utilization of job relocation to improve employee's work quality and achieving organizational goals, employees might be reluctant to be relocated. In some cases, the reluctance grow into stress that might results to burnout and job dissatisfaction. To investigate employee perception on job relocation, this study utilized qualitative phenomenology approach. Data were obtained from interviews involving 5 participants. Open ended question were asked to the participant to share the story about their job relocation history throughout their career in Alpha Corp. The results demonstrates employees' awareness on about the consequences of working in Alpha Corp. Although the job relocation's timing is unpredictable, employees would like the organization to consider the psychological impact for the transferred employees and the family, since frequent adaptations to new local cultures and work environment could lead to burnout and intention to quit from the organization. Other implication for managerial practice were discussed.
\end{abstract}

Keywords: Job relocations, job stress, Human Resources Management, phenomenology.

\section{INTRODUCTION}

In the current competitive era, company would relocate employees between subsidiaries to maintain the quality of competencies standard [1]. However, many employees prefer to resign from their job when they were asked to relocate [2]. In many cases, family consideration is the antecedent of employees' reluctance to relocate [3]. Relocation could separate employees and their families and could lead to workfamily conflict or family-work conflicts [4].

Job relocations could also stress the employees, since they are required to be able to adjust to a new environment and a new work culture in a relatively short period [5]. In addition, the compensation received by employees after the relocation is often viewed as unfavorable when they compared it with their new workload [6]. Some antecedents of the stress includes not being mentally ready for relocation, lack of working experience, afraid to make failure, being away from their family, and reluctance to move from the current working environment [7]. Previous research demonstrated that work transition can be a source of stress, associated with negative effects in terms of physical and psychological health that could reduce work motivation [8]. 
Despite job relocation phenomenon is often viewed as a common phenomenon, it is interesting to investigate employees' perceptions towards job relocations. To achieve this, case study from an Indonesian government organization, Alpha Corp, is utilized. Alpha is a government organization that collaborates with provincial and local government agencies engaged in the economics matter. The vital function of Alpha Corp has made the company to gather the status as an "employee champion". Fresh graduates and professionals dream to work in Alpha Corp, and the company has dozen of branches all over Indonesia.

Job relocations in Alpha Corp occur toward employees in all level. Generally, an employee would be able to retain their placement over a period of 2 years or even earlier. The high level of job relocation in the organization is one of the strategies to equally distributing talent in Alpha Corp and to improve the quality of the employees.

This study would investigate the phenomenon of job relocation in Alpha Corp which occurs on employees who enters and leaving Java Island. Java has become a favorite place for employees due to its excellent public infrastructure compared to other island in Indonesia. Furthermore, the study would like to investigate on the work commitment of employees experiencing transfer to or from Java Island.

\section{METHOD}

The present study utilizes a phenomenological approach in order to investigate employees' perception of Alpha Corp regarding their inter-island job relocations experience. None of the authors have experienced inter-island job relocation during their career, therefore, this study select participants who have experiencing inter-island job relocation. The participants should be diverse enough in order to obtain sufficient unique stories of the phenomena [9]. This study initially intended to recruit up to 10 participants. Nevertheless, obtaining participants, which fulfill the criteria established and willing to allocate sufficient time for an interview, is difficult. Based on such fact, this study employs the combination of convenience sampling and snowball sampling. Two participants were initially recruited by convenience sampling and afterwards they were asked to refer their acquaintances who match the criteria. The total participants in this study were 5 participants, all have experiencing job relocations at least once during 2014 to 2019. At the present times, three participants are married. Participants' identities were protected by using initial P1 to P5.

In order to obtain answers to the inter-island job relocation, the story of each participant was captured using face to face interview. Participants were interviewed off site in a place of their choosing after working hour. Each interview lasted for 0 to 50 minutes and was documented using voice recorders. The interview results were later transcribed and analyzed. Although the interviews were designed as a casual conversation with participants, researchers developed interview guidelines containing 37 probing questions to investigate the job relocation experiences of each participant based on the previous studies. Each interview was opened by asking respondents about their career journey in Alpha Corp. Afterwards, the interviewers ensure that the next questions should flow naturally based on the participants' answer to the first question. The interviewer utilizes probing to ensure that the answer of each respondent covers all topics in the interview guidelines. Each participant was free to tell their stories based on the first questions, although afterwards the interviewer sometimes intervenes by asking questions which are not part of the participant's initial story. Each interview was scrutinized and as the results; the themes were constructed as the reflection of the thematic experience of job-hopping from each participant.

\section{RESULT}

\subsection{Theme 1: Perception}

Participants have different perception related to their job relocation experience. Some feel happy (P1, P2, and P4), feel shocked (P5), and also feel disappointed (P2, and P3). For P2 and P3 participants, they responded negatively to the decision to be transferred because they have to left their closest people (future wife and parents). Nevertheless, P2 welcomed the second relocation since it was supported by his wife.

"Only one thing is in my heart, girlfriend. The job relocation occurred at the time when I was single, had not yet had a wife, but had been in a relationship with for 6 years. It is impossible not to feel worried that a relationship will be destroyed because we have to be separated. There are many failure stories from long distance relationships that I need to worry about. It was more difficult to leave your boyfriend than to leave your parents. Hahaha... (P2) ".

In the second job relocation, P2 was having the peace of mind because in addition to getting a promotion, his fiancée was also willing to go with him to West Sulawesi after they get married. On the other hand, P3 was hoping to be transferred to his hometown (Jakarta), but transferred to the Alpha Corp's branch in Central Java. P3's disappointment 
arose due to the differences between his expectation and the reality.

Apart from the responses given by the participants, the situation and changes in participants' long-term plans were only one of the factors that influenced their perception of the transfer decision. For example, in the case of P1; although he was happy returning to his hometown, he also had to readjust the long-term plans he had arranged with his wife (e.g., children's education, house investment, and round trip costs to the area of origin.

As previously stated, there were also participants who welcomed the transfer decision, as experienced by P1 and P2. They were pleased because they were transferred back to their hometown and received a promotion. They now have more opportunities to gather with their families and advance their careers.

When participants responded negatively to the job relocation process, it created a sense of stress in them which in turn had an impact on their work. When experiencing work stress, participants will experience several syndromes such as unstable emotions, uneasy feeling, troubled sleeping, excessive smoking, being unable to relax, anxiousness, tenseness, nervousness, increased blood pressure and experiencing indigestion. The majority of participants who were the sources in this study had the same response, namely nervousness and uneasiness.

The participants felt nervous and uneasy because they felt that they needed to reorganize everything related to family matters and long-term planning. This was conveyed by participants $\mathrm{P} 2$ and P5, participants $\mathrm{P} 2$ at the beginning received a decision to promote and transfer to Mamuju, participant P2 was worried because he was afraid that his wife was reluctant to come with him to the city of Mamuju.

Participant P5 also experienced an indicator of stress, namely uncommunicative. This happened when the P5 participant was transferred to the Alpha Corp's office in NTB. Participant P5 who is still a new employee at the NTB office feels unfamiliar with being in a new and unfamiliar environment, this makes the participant feel stressed and makes his communication worsen.

"... Yes, at the beginning of the job relocation, I tended to be uncommunicative because we didn't know, bro, we need to find out first what the character of each person is and after walking for about 2 years I am more open and I am also more understand about the character of each of my colleagues (P5) ".

Participant P5 responded negatively to the job relocation due to his discomfort with the new work environment and dissatisfaction to the timeline off the job relocation. P5 believed that he should not be transferred so soon, as told to him during the work interview. Being in a totally different environment, P5 experiencing cultural shock and begin to question his cultural identity and experienced prolonged anxiety.

The participants at the beginning of the job relocation experienced the affective dimension in culture shock where their emotions and feelings could turn into positive or negative. Participants P1 and P2 (the first job relocations was from Medan to Semarang) experiencing positive emotion, since they are returning to their hometown. For participants P3, $\mathrm{P} 4$, and P5, their emotions turns negative. These negative emotions and feelings came from differences in culture and work patterns that they had to go through in their new workplaces. Employees will go through a period of confusion and overwhelmed in unfamiliar environment. They feels anxious, confused and even feels unhappy when in the new environment.

Working in a new environment requires adaptation to the local culture and customs, as experienced by P2 and P5. Participant P2 is a Javanese who accustomed to casual work patterns has to get used to a more rigid and formal environment in Mamuju. In the case of participant P5, he previously worked at the Alpha's head office in Jakarta and accustomed to a competitive environment. In the head office, competition between workers are supposed to be "seen" and politicking are common to show working capability to the superior. In the new working environment, such actions are considered rude and ambitious. The ability to adapt to the new working environment would greatly affect the performance of the newly transferred employee.

\subsection{Theme 2: Adaptation}

In order to perform in the new working environment, transferred employees need to adapt to the culture of the organization and the society. Sometimes the adaptation process take a long period to occur. Of the five participants, the four participants namely $\mathrm{P} 1, \mathrm{P} 2, \mathrm{P} 3$, and $\mathrm{P} 4$ took less than 6 months to adapt to their new environment, while for P5 participants it took a year to adjust to their new environment. The differences and the length of time required for participants to adapt to their new environment cannot be separated from the obstacles they face while adapting to the new environment.

For participant P5, the obstacle for adaptation was caused by the difference of culture. People in the Jakarta head office were more open to discuss every matter, unlike the high context communication style 
of the people in NTB. The majority of his new colleagues are married, which creates a formal communication protocol with the younger colleagues. Despite the difficulty, his family always supports him which help P5 to maintain his mental health.

The role of direct superior and co-workers also has a major impact on the psychological of the participants. It was mentioned that the superiors of the five participants gave sincere attention by listening to and accepting the opinions of the participants. Also, despite some problems experienced by some participants, it turned out that the newly transferred employees were welcomed by the meet-and-greet session with their co-workers. Despite the differences in personality of the five participants, co-workers' supports are important so that the newly transferred employees would feel accepted by the new organization.

Good cooperation between colleagues certainly makes it easier for the five participants to adapt to new work patterns and rhythms. Conflicts could sometimes happen, as experienced by participants P2 and P5. Participant P2 has a relaxed nature and applies a casual and gentle approach through friendship to his team and colleagues in Mamuju. He did not treat his colleagues as harsh and rigid as the manager he replaced. However, P2 actually felt that because his approach method was contradictory to the Manager he replaced, made his colleagues underestimate the presence of $\mathrm{P} 2$ participants. This caused a conflict between $\mathrm{P} 2$ and his co-workers who took P2's presence lightly. In the case of participantP5 whose communication style are open and frank, his colleagues were often offended since they felt that P5 is a harsh and grumpy individual. Such conflicts were able to be solved eventually, due to the nature of the Indonesian in general who tend to avoid prolonged conflict in the workplace.

\subsection{Theme 3: Perceived Profit/Loss}

Based on the job relocations experience, the participants have their own perceptions of the job relocation decisions, namely from a profit-loss perspective. All participants received allowances, accommodation costs, and official housing from Alpha. They were all also agrees that job relocation is a path for faster career promotion, since new knowledge will be obtained. For those relocated near to their hometown, parents or families, the relocation would be seen as positive.

The drawback of the job relocation is the adjustment process due to the difference of culture among Indonesian provinces. Despite the recruitment process in Alpha Corp was determined by the Head Office in Jakarta, Alpha's employees were coming from diverse cultural background from various Indonesian ethnicities. Thus, when an employee from a certain ethnic is transferred to the region outside his/her home culture, they would be likely to experience cultural shock due to the difference in communication style, customs, and foods.

Another drawback is the longing for the family, since not every Alpha's employee will bring their families to the new job location. They often have to leave their families behind in the name of professionalism and job responsibilities. Such decision would have financial impact, since employees has to allocate extra airfare expenses to visit their families whenever possible.

\section{CONCLUSION AND MANAGERIAL IMPLICATION}

Based on the results from 5 participants working in Alpha Corp, this study concluded that there are three aspects of job relocation that needs to be given attention by the organization. The first aspect is related to employees' perception and reaction when they were relocated. Employee could feel elated or excited when hearing about the relocation, but could also disappointed, sad, anxious or stressed. Therefore, it is important for the organization to arrange an open discussion with the candidate that is going to be relocated [10]. Despite job relocation is a necessity for the organization, employee who have negative perception toward the relocation decision could experience depression which could lead to higher turnover for the organization [11].

The second aspect related to the adaptation process of the newly transferred employee with the local society as well as the organization. As Indonesia consists of 34 large ethnic groups, culture and customs in Indonesia vary by province [12]. Organization needs to provide pre-departure training about the culture and customs of the region, and provide assistance prior to their arrival [13]. Employee could quickly adapt with the culture and norms of the organization, as well as the accepted communication protocol among staffs, if they are provided with support and assistance from the local employee. The support and assistance could vary, such as mentoring for the junior employee by their senior which could eliminate the generational gaps [14]. For newly-transferred manager, their credentials has to be well informed to organization members, so that the staff would have respect and give warm welcome to their new superior.

The third aspect is related to how organization should understand the consequences of job relocation for their employee. Some employees regards job 
relocation as an expedite for career promotion. Also, employee's morale could be heightened especially when they are transferred to a preferable location (e.g., closer to family, transferred back to their hometown, transferred to Java Island, etc.). However, not all employees would regard job relocation as an opportunity. Many Alpha's employee choose to live separately from their spouse and children, which could cause financial problem since they have to spend extra transportation and living cost. Such condition could also lead to stress since the family would not be able to give direct support on their spouse's job-related and life-related problems [15]. The last consequence that needs to be aware of is when the employee considers job relocation at the same position in the organization as a sign of career stagnation [16].

Future research should involve participants from more diverse ethnic groups, since there might be a different perception toward job relocation from employees of different ethnicities.

\section{AUTHORS' CONTRIBUTIONS}

All authors contributed to the design and implementation of the research, to the analysis of the results and to the writing of the manuscript.

\section{ACKNOWLEDGMENTS}

The authors thank Diponegoro University and the Ministry of Education and Culture of the Republic of Indonesia for providing the Basic Research Scheme funding and assistance during the data collection.

\section{REFERENCES}

[1] H. Brynne, "Moving employee talent key to competitive edge," Strateg. HR Rev., vol. 15, no. 2, pp. 65-69, Jan. 2016, doi: 10.1108/SHR01-2016-0005.

[2] D. R. Dalton, "Employee Transfer and Employee Turnover: A Theoretical and Practical Disconnect?," J. Organ. Behav., vol. 18, no. 5, pp. 411-413, Jan. 1997, [Online]. Available: http://www.jstor.org/stable/3100212.

[3] A. G. Munton and N. Forster, "Job relocation: Stress and the role of the family," Work Stress, vol. 4, no. 1, pp. 75-81, Jan. 1990, doi: $10.1080 / 02678379008256967$.

[4] L. Mäkelä and V. Suutari, "Coping with workfamily conflicts in the global career context," Thunderbird Int. Bus. Rev., vol. 53, no. 3, pp. 365-375, May 2011, doi: https://doi.org/10.1002/tie.20414.
[5] K. Bhui, S. Dinos, M. Galant-Miecznikowska, B. de Jongh, and S. Stansfeld, "Perceptions of work stress causes and effective interventions in employees working in public, private and nongovernmental organisations: a qualitative study," BJPsych Bull., vol. 40, no. 6, pp. 318325, Dec. 2016, doi: 10.1192/pb.bp.115.050823.

[6] Kris, "Apakah Karyawan Boleh Menolak Mutasi?" 2013.

[7] F. Sprumont, A. S. Benam, and F. Viti, "Shortand Long-Term Impacts of Workplace Relocation: A Survey and Experience from the University of Luxembourg Relocation," Sustainability, vol. 12, no. 18, 2020, doi: https://doi.org/10.3390/su12187506.

[8] A. Sagie, M. Krausz, and Y. Weinstain, "To move or not to move: Factors affecting employees' actual relocation when an entire plant moves," J. Occup. Organ. Psychol., vol. 74, no. 3, pp. 343-358, Sep. 2001, doi: https://doi.org/10.1348/096317901167398.

[9] S. M. Laverty, "Hermeneutic phenomenology and phenomenology: A comparison of historical and methodological considerations," Int. J. Qual. Methods, vol. 2, no. 3, pp. 21-35, 2003, doi: $10.1177 / 160940690300200303$.

[10] R. Knight, "How to Decide Whether to Relocate for a Job," Harvard Business Review, 2018.

[11] R. Martin, “Adjusting to job relocation: Relocation preparation can reduce relocation stress," J. Occup. Organ. Psychol., vol. 72, no. 2, pp. 231-235, Jun. 1999, doi: https://doi.org/10.1348/096317999166626.

[12] S. Bazzi, A. Gaduh, A. D. Rothenberg, and M. Wong, Unity in Diversity?: Ethnicity, Migration, and Nation Building in Indonesia. Centre for Economic Policy Research, 2017.

[13] S. Lawson and J. Shepherd, "Utilizing the UCurve Model to Assess Cross-Cultural Training Programs for Low Context Expatriates Working in a High Context Culture," J. Bus. Divers., vol. 19, no. 1 SE-Articles, Apr. 2019, doi: 10.33423/jbd.v19i1.1352.

[14] J. F. Waljee, V. Chopra, and S. Saint, "Mentoring Millennials," JAMA, vol. 323, no. 17, pp. 1716-1717, May 2020, doi: 10.1001/jama.2020.3085.

[15] Y. K. Leung, J. Mukerjee, and R. Thurik, "The role of family support in work-family balance and subjective well-being of SME owners," $J$. Small Bus. Manag., vol. 58, no. 1, pp. 130-163, Jan. 2020,

doi: 
10.1080/00472778.2019.1659675.

[16] A. A.E., V. J., and S. D., "Career Stagnation: Underlying Dilemmas and Solutions in Contemporary Work Environments," in Work and Quality of Life. International Handbooks of Quality-of-Life, N. Reilly, M. Sirgy, and C. Gorman, Eds. Dordrecht: Springer, 2012. 